\title{
The Montreal General Hospital Pain Centre (1974 to 2000): The contributions of Ronald Melzack
}

Mary Ellen Jeans RN PhD ${ }^{1}$, Joseph Stratford MD FRCSC ${ }^{2}$, Paul Taenzer $\mathrm{PhD}^{3}$, Sandra Lefort RN $\mathrm{PhD}^{4}$, Kathleen Rowat RN, $\mathrm{PhD}^{5}$

ME Jeans, J Stratford, P Taenzer, S Lefort, K Rowat.

The Montreal General Hospital Pain Centre (1974 to 2000):

The contributions of Ronald Melzack.

Pain Res Manage 2000;5(3):223-227.

This paper chronicles the development of the Montreal General Hospital Pain Centre from its inception in 1974 to the present. Highlighted in particular are the contributions of Ronald Melzack to this history. Data for the article arose, in the main, from an interview with Dr Melzack carried out earlier in the year. Discussions with former and present members of the pain centre team, including former graduate students, provided additional information. The article begins with a recounting of those individuals and events that inspired Ron early in his 'pain career' to pursue his dream of a multidisciplinary pain centre, the first of its kind in Canada. The forces that helped shape the development of this centre and the challenges that had to be overcome are described.

Key Words: Montreal General Hospital Pain Centre; Ronald Melzack

\section{Clinique de douleur chronique de l'Hôpital général de Montréal (1974 à 2000) : l'apport de Ronald Melzack}

Le présent article retrace l'historique de la Clinique de douleur chronique de l'Hôpital général de Montréal, depuis ses débuts en 1974 jusqu'à maintenant. Y fait figure de proue Ronald Melzack. Les faits ont été tirés, dans l'ensemble, d'une entrevue faite avec le $\mathrm{D}^{\mathrm{r}}$ Melzack, plus tôt cette année. À cela s'ajoutent des commentaires provenant de membres passés et actuels de la Clinique, dont d'anciens diplômés. L'article commence par la description des personnes et des événements qui inspiré Ron au début de sa « douloureuse » carrière et qui l'ont poussé à réaliser son rêve de mettre sur pied une clinique antidouleur multidisciplinaire, la première du genre au Canada. Voici comment les forces vives ont permis à la Clinique de voir le jour et quels défis ont dû être relevés.

\begin{abstract}
Ompassion for those suffering and a passion for knowledge characterize Ronald Melzack. These were the driving forces that led Ron ultimately to realize his dream of a multidisciplinary pain centre - the first of its kind in Canada. In a recent interview with Dr Melzack concerning the history of the centre, a picture of dogged determination emerged as he recounted the years leading up to the initiation of the centre, the forces that shaped its development and the challenges that had to be overcome.
\end{abstract}

\section{THE BEGINNING OF AN IDEA}

Ron's recounting of the history of the pain centre began with his description of the years 1954 to 1957 , which he spent with WK Livingston in Portland, Oregon. As Ron spoke, it was clear that Livingston was a major influence in his life and in large measure was responsible for the ultimate direction of Ron's career. Dr Livingston was an active basic scientist and the chair of surgery at the University of Oregon Medical School. It was to Livingston's laboratory that Ron was first

\footnotetext{
${ }^{1}$ Canadian Nurses Association, Ottawa, Ontario; ${ }^{2}$ Department of Neurosurgery, Montreal General Hospital, Montreal, Quebec; ${ }^{3}$ Calgary Chronic Pain Centre, Calgary, Alberta; ${ }^{4}$ Memorial University of Newfoundland, St Johns, Newfoundland; ${ }^{5}$ Rowat Consulting, Ottawa, Ontario Correspondence and reprints: Dr Mary Ellen Jeans, Canadian Nurses Association, 50 The Driveway, Ottawa, Ontario, K2P 1 E2. 
attracted in 1954. One year later, Livingston invited Ron to join him in his multidisciplinary pain clinic. Ron quotes Livingston as saying, "this is where you will really learn what pain is all about". According to Ron, Livingston's pain clinic was "one of the great pain clinics in the world, although not many were aware of it". At that time, Livingston's clinic was one of only two in existence in North America (Bonica's in Tacoma, Washington being the other). It was here, according to Ron, that "he had a feel for the real power of a multidisciplinary pain clinic", a place where 'hope' played a central role. Livingston's multidisciplinary pain clinic would become the model to which Ron would aspire in later years as he went about setting up the pain centre at the Montreal General Hospital. During his time in Livingston's Pain Clinic, Ron experienced an important event, one that would set the course for much of his future research in the area of pain. Ron met the first patient he had seen with phantom limb pain. As Ron recounts, this patient "had a wonderful vocabulary" to describe her pain. Ron began jotting down her words, "not knowing at the time what it all meant or what I would do with it". This encounter led ultimately to the development of the McGill Pain Questionnaire.

It was during a period of time at the Massachusetts Institute of Technology (MIT), Cambridge, Massachusetts (1959 to 1963), where Ron served as assistant and then associate professor of psychology, that another important association significant to Ron's career was formed. It was here that Ron met Patrick Wall. Together, they developed the gate control theory of pain (1). While the gate control theory of pain revolutionized the neuropsychological understanding of pain and led to an explosion of basic research, it also provided a conceptual model for approaching the treatment of pain from a multidisciplinary perspective. Ron left MIT in 1963 and returned to Montreal and to McGill University, where he began the journey that would ultimately lead to the creation of the multidisciplinary pain treatment centre at the Montreal General Hospital.

\section{THE IDEA TAKES SHAPE}

At McGill University, Ron set about establishing his laboratory to continue his work in the field of phantom limb. Ron recalls that, at about the same time, his wife experienced phantom sensations following the birth of one of their children. This further contributed to Ron's curiosity concerning the subject. A meeting with Dr Phillip Bromage, then head of anesthesiology at McGill University and the Royal Victoria Hospital in Montreal, led to their joint experimental endeavours with phantom limb pain $(2,3)$. Ron remembers trying, from time to time, to engage Bromage's interest in the matter of a multidisciplinary pain centre modelled after Livingston's pain clinic in Portland. After some time, Bromage announced to Ron that the dean (Dr Maurice McGregor) had "given his go-ahead" and that they could set up a pain clinic at the Royal Victoria Hospital. Thus, in 1972, through the efforts of this 'team of two' ("Bromage doing the blocks and me contributing the ideas") Ron's dream began taking shape. Then, as now, people were intrigued that a basic scientist was concerned with the clinical aspect of pain management. To the question, "was this unusual?", Ron's answer was, and is, a brief "yes". However, it perhaps was not unusual given the strong role model he had had in Livingston, who himself was a basic scientist.

Along with 'hands on care', teaching and research were important aspects of the work of this clinic, just as they would be in the centre established later at the Montreal General Hospital. Two of Ron's graduate students (Paul Taenzer and Mary Ellen Jeans) became involved in the Royal Victoria Pain Clinic - Mary Ellen, with an interest in the effects of transcutaneous electrical nerve stimulation on pain, and Paul, who was working with Ron on the McGill Pain Questionnaire. As he described these early days, Ron recalls walking into an examination room in which one of these students was carrying out a pain assessment. The student was staring into empty space, asking the patient who had had a below-knee amputation, to move his foot and toes. The student's initial reaction at seeing Ron was one of embarrassment. However, she was hastily assured by Ron that he knew exactly what she was doing. An important lesson had been learned - phantom limbs were 'real'!

During these years at the Royal Victoria Hospital, Ron formed important associations with other people interested in the treatment of pain. One of these people was Balfour Mount. Mount's work in the area of palliative care and the management of pain ultimately led the two to collaborate in studies that looked at the effect of different approaches to analgesic preparation for terminally ill patients $(4,5)$.

With the departure of Dr Bromage for Colorado, and the subsequent change of personnel and philosophies of pain management and research in the clinic, it became clear to Ron that a new setting was necessary if he were to launch the multidisciplinary pain centre that he envisaged. Also central to the decision to move was Ron's concern that the conditions necesssary for his graduate students to carry out their research be in place. Fortuitously, Mary Ellen Jeans' field experience as a graduate student in psychology and her parttime work as a registered nurse had taken her to the Montreal General Hospital, where she met Dr Joseph Stratford, chief of neurosurgery at the hospital. Mary Ellen reported to Ron that she felt that she had met someone who appeared to understand what they were trying to achieve in the establishment of a pain service and who, by virtue of his own clinical work, was no stranger to the problems of chronic pain. "Once I met him, I was smitten", says Ron. Thus began a long association that continues to this day. In large measure, it was through the efforts of Dr Stratford, who negotiated and convinced the administration of the hospital of the importance of a pain treatment centre, and 'fought' to procure space for the centre, that the "dream' became a reality.

\section{THE DREAM UNFOLDS}

As plans for the multidisciplinary centre were unfolding, the gate control theory of pain was becoming more popular and provided the necessary conceptual framework upon which the multidisciplinary approach to pain could be justified. 
Gradually a 'team' was formed, representing a variety of services concerned with the problem of pain, such as anesthesiology, neurosurgery, psychology, psychiatry, nursing, physiotherapy and social work. Contact with the Department of Dentistry was established early in the development of the centre and led to another area of research (6). Visiting researchers and postdoctoral fellows working with Ron became part of the team from time to time. However, as one of the team members from those early days recalled:

It took time for us to understand and respect the varying paradigms each of us brought to the problem of pain.

We had to learn how to work together for the benefit of the patient.

Listening to Ron and to some of the original team members, it is evident that their hard work paid off. A picture of 'good chemistry' emerges and, as they all repeated many times, "we had a good time". One of the challenges facing the team was what to call the service. The choice of the name 'centre' rather than 'clinic' was, according to Ron, a very purposeful one. "Centre denotes something larger than a clinic". Indeed, the centre was not just a clinical service but also a place for active clinical research and teaching.

From the beginning, there was a close interplay among research, education and the delivery of patient care. As Ron remarked in an interview, "the intertwining of these elements was a crucial factor in the success of the centre". This idea went along with the shared belief that it was the patient in pain who was central to all of their efforts. "We wanted to create a place where people with chronic pain would find a listening ear". The overriding philosophy of the centre was that, " if a patient says he or she is in pain we have no reason to doubt him (her). We believed they were in pain". Like Livingston, Ron wanted the centre to be seen as 'home'- a place where the patient "would be believed". All too often, as Ron pointed out, these patients had had prior experiences with health professionals that had been negative, with the patient's pain essentially being discounted.

The Montreal General Hospital Pain Centre opened its doors officially in 1974, with Mary Ellen Jeans as coordinator and staff psychologist. Dr Stratford served as chief of the service arm of the centre, and Ron was responsible for the research programs. However, as an article describing this new service in the 1975 spring issue of the Montreal General News reported, all members of the group (team) " share responsibility for the functioning of the Service". There were no restrictions as to who could be seen at the centre. Any patient with a chronic pain problem was eligible for admission. Over the years, however, the preponderance of patients seen were those reporting back pain. Patients were mainly outpatients, although consultation services were provided for pain management problems for inpatients. Approximately 500 patients and families were assessed each year, and a large number of these people were seen regularly for many years by various members of the centre staff.

For Ron and other members of that early team, there were patients who were particularly memorable, including the very first patient seen at the centre. This patient had managed to self-inflict wounds with tourniquets so that his legs had to be amputated, one after the other. Not surprisingly, he suffered severe phantom limb pain. Another patient reported severe pain following excessive radiation for breast cancer. The pain was thought to be the result of brachial plexus damage that left her arm dysfunctional. She perceived a painful phantom arm, which was positioned at a $45^{\circ}$ angle from her real elbow. She was a delightful, positive person despite her suffering, and was willing to participate in research activities and education sessions in the centre.

An important feature of the ongoing work of the centre, and one that even today Ron and other team members speak of with enthusiasm, was the weekly patient rounds. It was during these rounds that the team members (clinicians and researchers), students from Ron's McGill laboratory, the patient and often the patient's family, all with their varying perspectives on pain, came together to find ways of dealing with the patient's pain. It was here that the true value of multiple disciplines working together to solve the puzzle of pain could be seen.

There were also the 'less formal' sessions, which, as Ron's former graduate students recall, formed a valuable part of their learning experience. These were the Friday afternoon 'research seminars' held at Riemark's (and later Toe Blake's) Tavern. There was just one problem with these sessions only men could be admitted to a tavern in Quebec. This led to the enterprising female member of the team dressing up as a man and boldly accompanying her male colleagues to the tavern. It should be noted that she apparently went undetected by the staff and other patrons of the tavern. As a postscript to this story, taverns eventually were reclassified as brasseries - establishments to which women could be admitted - so clandestine activities were no longer needed.

These early days were not without their challenges. Convincing others of the value of a multidisciplinary approach to the management of pain was a fundamental challenge. Gradually, however, over the years, a 'pain awareness', as Ron describes it, developed at the Montreal General Hospital.

Although treating chronic pain was seen as serious business by those in the centre, there were also moments of levity. On one occasion, Ron sent three of his graduate students off to a pain conference in Saskatchewan to enlarge their understanding of the problem of pain. They returned from the conference with copious notes and with much enthusiasm reported to Dr Stratford that they had learned of a new syndrome - 'prairie farmer's syndrome'. Needless to say, Dr Stratford was puzzled, until he realized that what they really were talking about was piriformis syndrome.

The research productivity of the centre was impressive, and added to the viability and vitality of the service. Ron, along with his graduate students, continued their work on phantom limb pain $(7,8)$, the use of trans-cutaneous electrical stimulation (9), psychological factors affecting postoperative pain (10), pain associated with burns (11), pain in the elderly (12) and the development of the McGill Pain Questionnaire 
to name a few. The effects of chronic pain on the family (13) became the focus of one of the team members. The centre provided the stimulus for many of these research ideas. Postdoctoral students arriving to work with Ron brought their interest and expertise dealing with such topics as trigger points and acupuncture. While there is no accurate record of the publications of all the people associated with the centre, there are in excess of 80 publications on Ron's curriculum vitae, which can be directly attributed to clinical research conducted at the centre.

It is readily apparent when talking with Ron that he has great pride in the work and ongoing success of his graduate students. It is equally clear that the energy and support that he brings to their efforts are major forces in their development and by extension to the development of the centre. This support and encouragement are not restricted to his students. To colleagues, both clinicians and researchers, he is generous with his praise and quick to acknowledge their contributions. As Ron traced the history of the pain centre for the interviewer, his enthusiasm was contagious - no doubt another important ingredient of the success of the work he has undertaken.

\section{THREATS TO EXISTENCE}

Despite its many successes, both in terms of the care provided to the patients and research productivity, the centre throughout its history was plagued with a number of threats to its existence. Finding adequate space in which to work, locating personnel prepared and able to commit full-time to work in the field of pain, and securing funding were some of the major hurdles to be overcome. In terms of funding, it is important to note that, in the early years of the centre's existence, monies for its operation came from Ron's research grants. Later, support from a private foundation enabled the clinic to continue for a period of time.

\section{'THE FIVE-YEAR HIATUS'}

Unfortunately, the threat of closure of the centre due to a lack of funding became a reality in December 1981. The administration of the hospital issued a statement to the effect that the present hospital budget constraints made it impossible to envisage funding from the hospital. Ron describes this as the beginning of 'a five-year hiatus'. The announcement of the centre's closing prompted a flurry of letters from both the community and health professionals who had witnessed the value of its work.

Not long after the announcement of the centre's closing, there were indications that the hospital administration was reconsidering its decision. It was then proposed that the service of the pain centre fall within the framework of the Division of Family Medicine. However, as Mary Ellen noted in her response to this proposal, "it [the new service] will of necessity be somewhat different from the service we have operated for the past 7 years".

The arrival of Dr William Davis in the spring of 1983 as the new chairman of family medicine led to renewed hope that a pain service within this department (proposed approximately a year earlier) might become a reality. Particularly en- couraging also was that Dr Davis' interest and prior work had been in the field of pain. Nevertheless, the issue of funding for such a service remained in the forefront.

By the latter half of the 1980s, a 'reconstituted' pain service had been established, functioning primarily as a consultation service. This 'pain clinic', as it was now called, provided assessment services followed by advice on treatment plans. The referring doctor was expected to implement the recommendations made by the clinic staff. In the absence of an operating budget, patients were charged an assessment fee to cover any expenses not covered by medicare. Once again, the service became multidisciplinary in its approach to the problem of pain with representatives from family medicine, anesthesiology, psychiatry, psychology, physiotherapy and neurosurgery forming the team.

\section{NEW BEGINNINGS}

The early 1990s saw the beginning of yet another phase in the history of the pain centre. Thanks to the fund-raising efforts of Alan Edwards and the generosity, once more, of a private foundation, the McGill-Montreal General Hospital Pain Centre was established in 1992. It is interesting to note, however, that there was a condition attached to this funding; the hospital was required to provide space within a 'reasonable time' for the work of the centre. Clearly, the problem of adequate space that had plagued the centre from its inception remained.

The McGill-Montreal General Hospital Pain Centre currently operates much as it did at its peak in the late 1970s. Dr Anneli Vainio brings a background in anesthesiology and palliative care to her current position as director of the service. Dr Ann Gamsa continues to play an important role as the psychologist on the team. Drs Stratford and Melzack remain key participants along with a group of new players representing several disciplines. Patient care, research and education remain equal partners in all centre activities. Funding is more secure, and the future perhaps more certain. A promising development is the recent commitment by Dr Franco Carli, chairman of anesthesia at McGill University, to have the pain centre placed under the umbrella of his department, establishing roots to the new McGill University Health Centre.

During the period of evolution of the McGill-Montreal General Hospital Pain Centre from 1974 to the present, the health care system itself has changed. Over the past 10 years, the federal contribution to health, social programs and postsecondary education has been cut dramatically. In response, provinces have undertaken changes or reforms of health care that have been fiscally driven, resulting in cutbacks in personnel and services. Pain continues to be a central and growing health care problem, often in the absence of a medical diagnosis. As Canada's aging population continues to grow and the incidence of chronic illnesses rises, pain remains a leading cause of health care use.

Despite the progress made over these many years in research and treatment, pain, both acute and chronic, continues to be undertreated $(14,15)$, undervalued in its significance and ignored by patient advocate groups (who tend to be or- 
ganized around disease entities), and policy and decision makers at all levels of government. Given the prevalence of pain, the long term negative effect of undertreatment (16) and the use of large amounts of health care resources, this stands in stark contrast to public and political commitment to a publicly funded, sustainable health care system. What undoubtedly is required is serious documentation of the prevalence, incidence and cost of pain and pain-related disability in Canada. Large scale epidemiological research, information systems that capture data on pain and a focus on pain by the Canadian Council of Health Services Accreditation, are needed. Educators and regulators of health professionals also

\section{REFERENCES}

1. Melzack R, Wall PD. Pain mechanisms: A new theory. Science 1965;150:971-9.

2. Melzack R, Bromage PR. Experimental phantom limbs. Exp Neurol 1973;39:261-9.

3. Bromage PR, Melzack R. Phantom limbs and body schema. Can Anesth Soc J 1974;21:267-74.

4. Mount BM, Mackinnon KJ, Melzack R. The management of intractable pain in patients with advanced malignant disease. J Urol 1978;120:720-5.

5. Melzack R, Mount BM, Gordon JM. The Brompton mixture vs morphine solution given orally: effects on pain. CMAJ 1979;435-8.

6. Bentley K, Camarda AJ, Melzack R, Morgan P, Roy C. Floctafenine, acetaminiphen/codeine combinations and placebo in dental pain. Curr Ther Res 1991;49:147-54.

7. Melzack R, Katz J. Amputation and phantom limb pain. In: Baum A, Newman S, Weinman J, West R, McManus C, eds. Cambridge Handbook of Psychology, Health and Medicine. Cambridge: Cambridge University Press, 1997.

8. Melzack R, Israel R, Lacroix R, Schultz G. Phantom limbs in people with congenital limb deficiency or amputation in early childhood. Brain 1997;120:1603-20.

9. Jeans ME. Relief of chronic pain by brief, intense transcutaneous electrical stimulation: A double-blind study. In Bonica JJ, have an important role in ensuring that curricula and professional examinations reflect the significant role of pain in the overall health care system.

Despite the downsizing of the health care system, there are currently several pain clinics and a few academically based pain centres in Canada. Many embrace the philosophy of a multidisciplinary perspective on pain that has been demonstrated to be effective (17). Ron Melzack's pioneering work in the establishment of a multidisciplinary pain centre in Montreal no doubt has served as the inspiration for such developments. To Ron, the 'world of pain' owes a debt of gratitude for his vision, commitment and leadership.

Liebeskind JC, Albe-Fessard DG, eds. Advances in Pain Research and Therapy: Proceedings of the Second World Congress on Pain. New York: Raven Press, 1979:601-6.

10. Taenzer P, Melzack R, Jeans ME. Influence of psychological factors on postoperative pain, mood and analgesic requirements. Pain 1986;24:331-42.

11. Choiniere M, Melzack R, Rondeau J, Girard N, Paquin MJ. The pain of burns: characteristics and correlates. J Trauma 1989;29:1531-9.

12. Gagliese L, Melzack R. Chronic pain in elderly people. Pain 1997;70:3-14.

13. Rowat KM, Knafl KA. Living with chronic pain: the spouse's perspective. Pain 1985;23:259-71.

14. Lister BJ. Dilemmas in the treatment of chronic pain. Am J Med 1996;101:2S5S.

15. Abbott FV, Gray-Donald K, Sewitch MM, Johnson CC, Edgar L, Jeans ME. The prevalence of pain in hospitalized patients and resolution over six months. Pain 1992;50:15-28.

16. Melzack R. The tragedy of needless pain. Sci Am 1990;262:27-33.

17. Turk DC. Efficacy of multidisciplinary pain centers in the treatment of chronic pain. In: Cambell JN, Cohen MJ, eds. Pain Treatment Centers at the Crossroads: A Practical Conceptual Reappraisal. Seattle: IASP Press, 1996. 


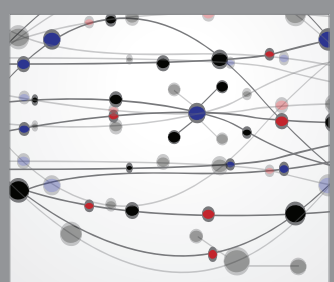

The Scientific World Journal
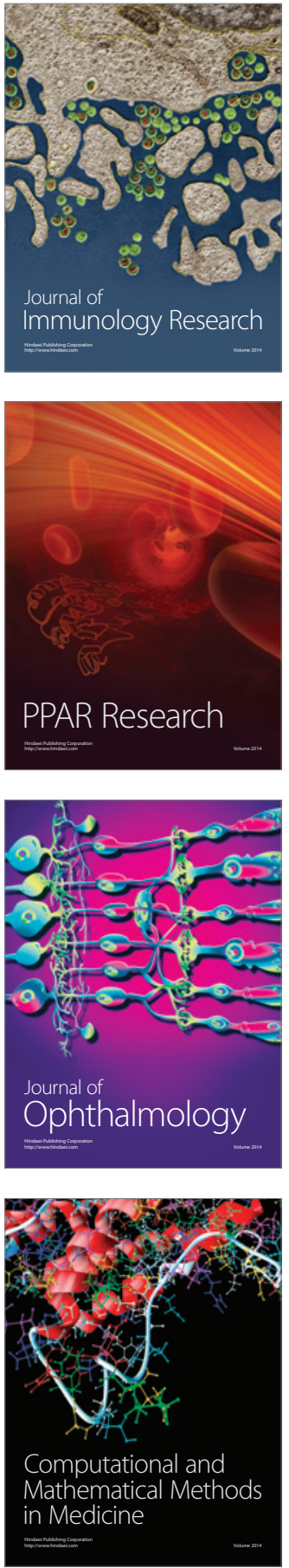

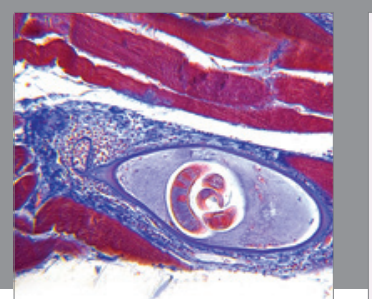

Gastroenterology Research and Practice

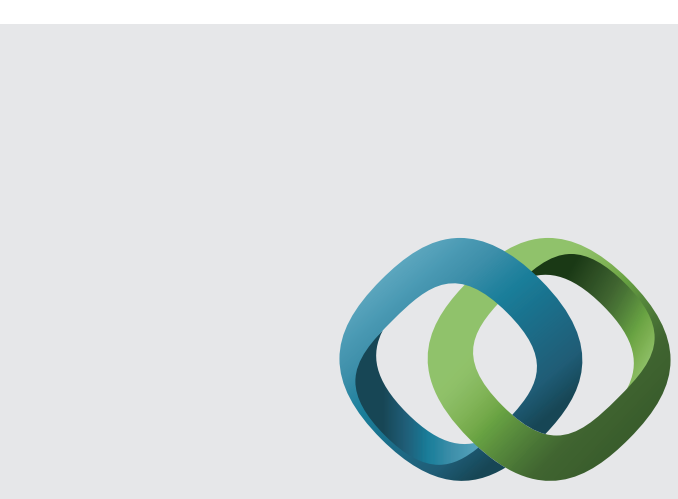

\section{Hindawi}

Submit your manuscripts at

http://www.hindawi.com
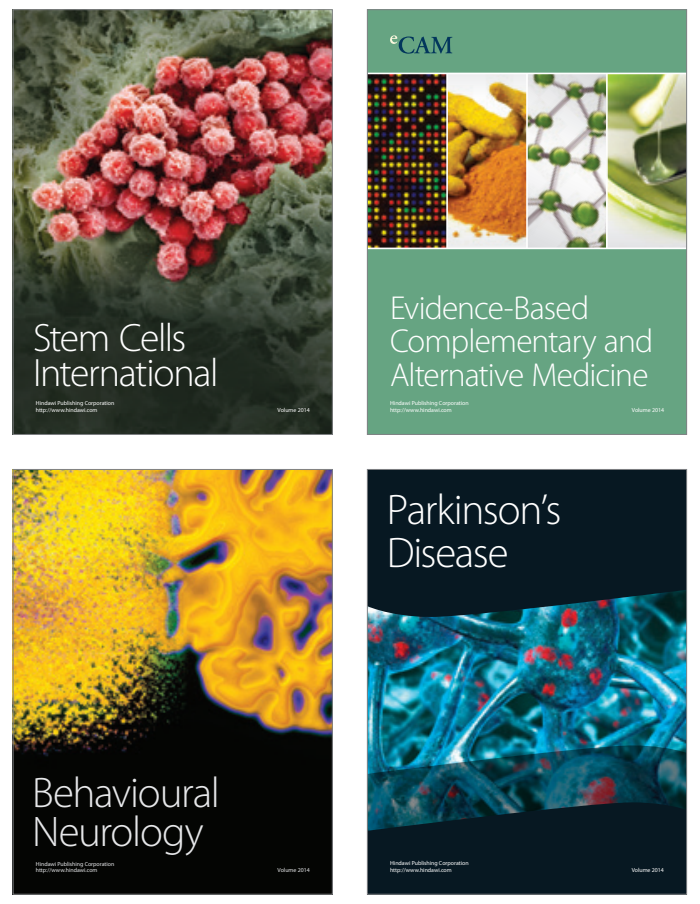
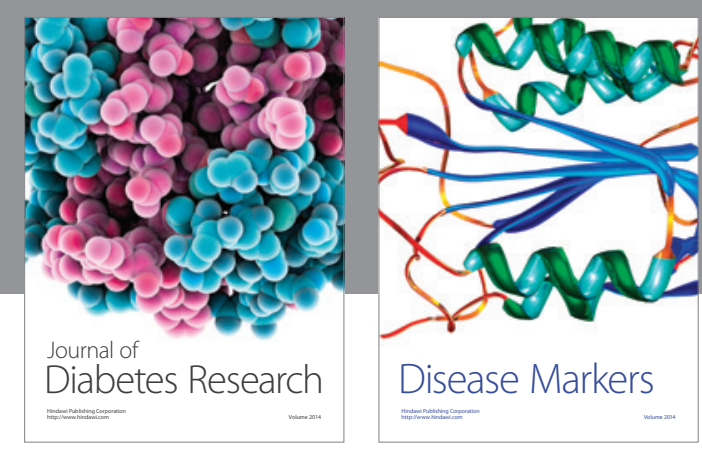

Disease Markers
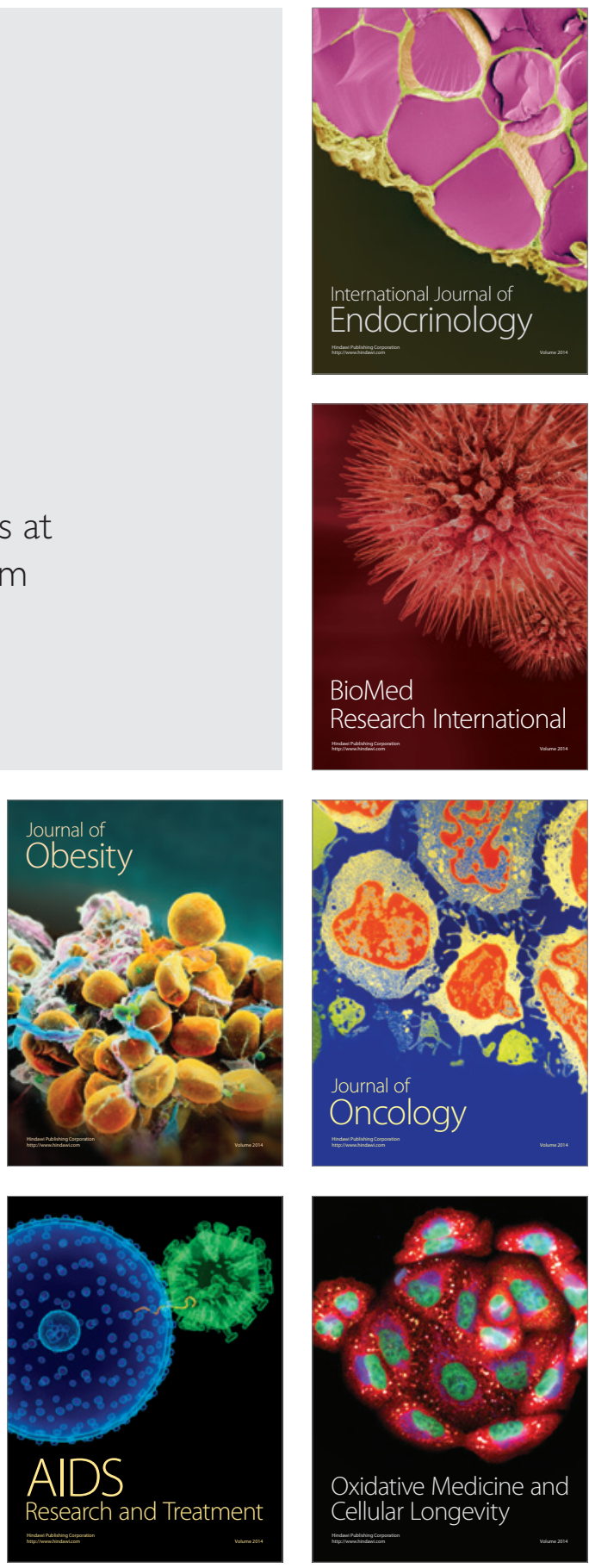